\title{
Determination of Sodium Cromoglycate by a New Kinetic Spectrophotometric Method in Biological Samples
}

\author{
Mohsen Keyvanfard, ${ }^{1}$ Khadijeh Alizad, ${ }^{1}$ and Razieh Shakeri ${ }^{2}$ \\ ${ }^{1}$ Department of Chemistry, Majlesi Branch, Islamic Azad University, Isfahan 8631656451, Iran \\ ${ }^{2}$ Department of Chemistry, Shahreza Branch, Islamic Azad University, Isfahan 8614773366, Iran \\ Correspondence should be addressed to Mohsen Keyvanfard; keyvan45638@yahoo.com
}

Received 29 May 2013; Revised 9 July 2013; Accepted 9 July 2013

Academic Editor: Antonio Manuel Romerosa-Nievas

Copyright (c) 2013 Mohsen Keyvanfard et al. This is an open access article distributed under the Creative Commons Attribution License, which permits unrestricted use, distribution, and reproduction in any medium, provided the original work is properly cited.

\begin{abstract}
A new kinetic spectrophotometric method is described for the determination of ultratrace amounts of sodium cromoglycate (SCG). The method based on catalytic action of SCG on the oxidation of amaranth with periodate in acidic and micellar medium. The reaction was monitored spectrophotometrically by measuring the decrease in absorbance of the amaranth at $518 \mathrm{~nm}$, for the first $4 \mathrm{~min}$ from initiation of the reaction. Calibration curve was linear in the range of $4.0-36.0 \mathrm{ng} \mathrm{mL}^{-1} \mathrm{SCG}$. The limit of detection is $2.7 \mathrm{ng} \mathrm{mL}^{-1}$ SCG. The relative standard deviation (RSD) for ten replicate analyses of 12,20 , and $28 \mathrm{ng} \mathrm{mL}^{-1} \mathrm{SCG}$ was $0.40 \%, 0.32 \%$, and $0.53 \%$, respectively. The proposed method was used for the determination of SCG in biological samples.
\end{abstract}

\section{Introduction}

Sodium cromoglycate, 5,5' -[(2-hydroxy-1,3-propanediyl)bis (oxy)]bis(4-oxo)-4H-1-benzopyran-2-carboxylic acid disodium salt is commonly used in the treatment of both extrinsic and intrinsic bronchial asthma [1]. A number of methods were developed for the determination of cromoglycate, including LC-MS-MS [2] and striping voltammetric [3]. These methods either lack sufficient sensitivity or are time consuming. A number of procedures have already been described for the measurement of SCG in biological samples such as polarography [4], radioimmunoassay [5], enzymelinked immunosorbent assay [6], and HPLC $[7,8]$. These methods require pretreatment for solvent extraction and/or lack sensitivity. The aim of the present study was to develop a sensitive, fast, and economy-analytical method for determination of SCG. Here, we report a kinetic spectrophotometric method for ultratrace determination of SCG, based on its catalytic effect on the oxidation of amaranth by $\mathrm{KIO}_{4}$ in the acidic and micellar mediums.

\section{Experimental}

2.1. Reagents and Solutions. All chemicals were of analytical-reagent grade and were provided by Merck and all the solutions were prepared with double distilled water. Working solutions were prepared daily from stock solutions $(1 \mathrm{~g} / \mathrm{L}$ for sodium cromoglycate, $0.001 \mathrm{M}$ for amaranth, $0.01 \mathrm{M}$ for $\mathrm{KIO}_{4}$, and $0.01 \mathrm{M}$ for tetrabutyl ammonium bromide (TBAB) solution. The other surfactants tested, namely, Triton X-100, sodiumdodecyl sulphate (SDS), cetyltrimethyl ammonium bromide (CTAB), hexadecylpyridinium bromide (HDPB), and hexadecylpyridinium chloride (HDPC) were prepared in a similar way. Amaranth and SCG have the structure shown in Figure 1.

2.2. Apparatus. Absorption spectrum was recorded with a CECIL model 7500 spectrophotometer with a $1.0 \mathrm{~cm}$ quartz cell. A model 2501 CECIL spectrophotometer with $1.0 \mathrm{~cm}$ glass cuvette was used to measure the absorbance at a fixed wavelength of at $518 \mathrm{~nm}$. A thermoelectric controller (CE 2024 CECIL) was used to keep the reaction temperature at $25^{\circ} \mathrm{C}$. A stopwatch was used for recording the reaction times.

2.3. Sample Preparation. The urine sample was stored in a refrigerator immediately after collection. Ten milliliters of the sample was centrifuged for five $\min$ at $2000 \mathrm{rpm}$. The supernatant was filtered through a $0.45 \mu \mathrm{m}$ filter and then diluted 10 times with water. The solution was transferred into 
<smiles>O=C(O[Na])c1cc(=O)c2c(OCC(O)COc3cccc4c3C(=O)CC(C(=O)[O-])O4)cccc2o1</smiles>

(a)

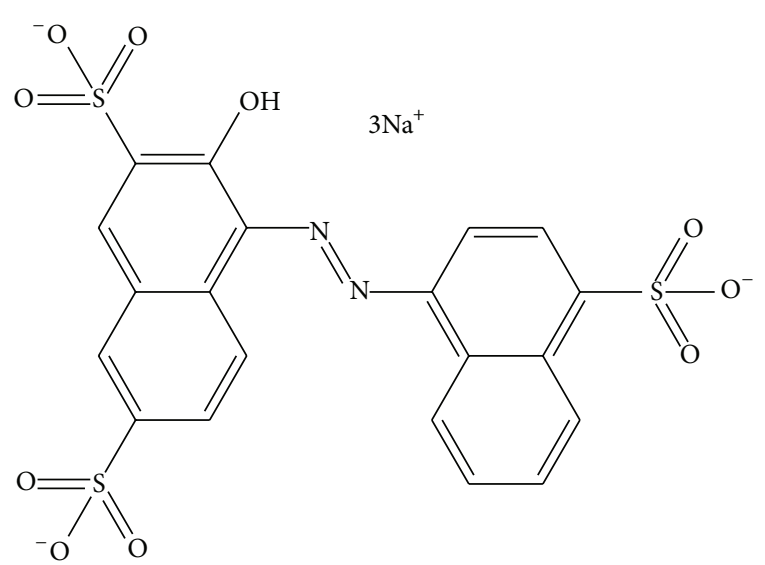

(b)

FIgURE 1: Structure of (a) SCG and (b) amaranth.

a spectrophotometric cell to be analyzed without any further pretreatment. Mineralization of $2 \mathrm{~mL}$ of the human serum samples was carried out for $1 \mathrm{~h}$ at $100^{\circ} \mathrm{C}$ with the addition of $4 \mathrm{~mL}$ of concentrated nitric acid $[9,10]$. Then samples were analyzed directly after neutralization with sodium hydroxide solution and diluted with double distilled water to a suitable volume. For recovery test, the necessary standards were spiked in samples at this stage.

2.4. Recommended Procedure. All the solutions and distilled water were kept in thermostated water bath at $25 \pm 0.1^{\circ} \mathrm{C}$ for $30 \mathrm{~min}$ before starting the experiment. An aliquot of the solution containing $4.0-36.0 \mathrm{ng} \mathrm{mL}^{-1}$ cromoglycate was transferred into a $10 \mathrm{~mL}$ volumetric flask, and then $2.6 \mathrm{~mL}$ of sulfuric acid solution $9.1 \mathrm{M}, 1.0 \mathrm{~mL}$ TBAB $0.01 \mathrm{M}$, and $0.4 \mathrm{~mL} \mathrm{KIO}_{4} 0.01 \mathrm{M}$, and $1.4 \mathrm{~mL}$ amaranth $1.0 \times 10^{-3} \mathrm{M}$ were added to the flask, and the solution was diluted to the mark with water. The solution was mixed and a portion of the solution was transferred into the spectrophotometric cell. The reaction was followed by measuring the decrease in the absorbance against water for $0.5-4.0 \mathrm{~min}$ from initiation of the reaction at $518 \mathrm{~nm}$. The signal was labeled as $\Delta \mathrm{A}_{\mathrm{s}}$. The same experiment was repeated without cromoglycate to get the blank signal, and it was labeled as $\Delta \mathrm{A}_{\mathrm{b}}$. Time was measured just after addition of the last drop of amaranth. The calibration graph was constructed by plotting of $\left(\Delta \mathrm{A}_{\mathrm{s}}-\Delta \mathrm{A}_{\mathrm{b}}\right)$ versus cromoglycat concentration at a fixed time of $0.5-$ $4.0 \mathrm{~min}$ from initiation of the reaction.

\section{Results and Discussion}

Amaranth undergoes an oxidation reaction with periodate in the acidic medium at a very slow rate. We found that in the presence of tetrabutyl ammonium bromide (TBAB) as a micellar medium, this reaction rate is sharply increased by the addition of trace amounts of SCG. There are many methods, such as fixed time, initial rate, rate constant, and variable time methods for measuring the catalytic species. Among these,

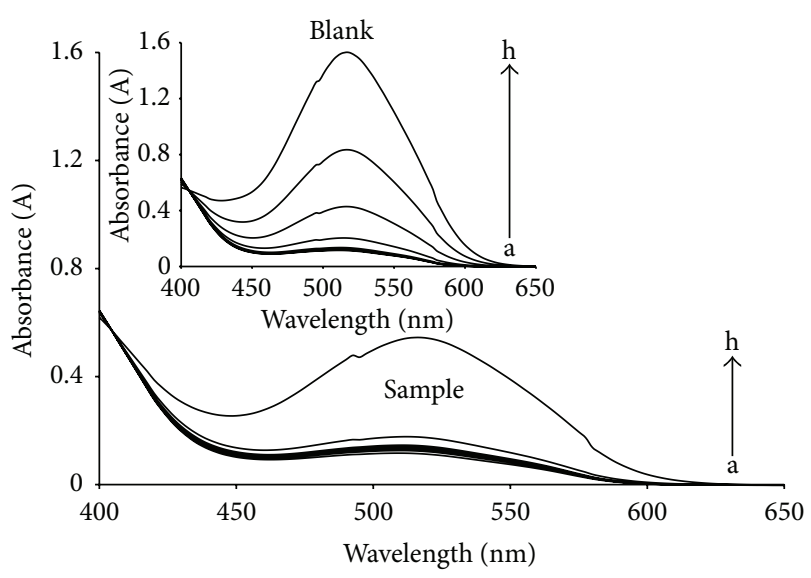

FIgURE 2: Absorption spectrum for the SCG-amaranth- $\mathrm{IO}_{4}{ }^{-}$system with time. Conditions: $\mathrm{H}_{2} \mathrm{SO}_{4}, 2.4 \mathrm{~mol} \mathrm{~L}^{-1}$; $\mathrm{SCG} ; 12 \mathrm{ng} \mathrm{mL}^{-1}$; $\mathrm{TBAB}$, $1.0 \times 10^{-3} \mathrm{M}$; amaranth, $1.4 \times 10^{-4} \mathrm{M} \mathrm{IO}_{4}^{-} 4.0 \times 10^{-4} \mathrm{M}$; temperature, $25^{\circ} \mathrm{C}$ interval time for each scan, and $0.5,1.0,1.5,2.0,2.5,3.0,3.5$, and $4.0 \mathrm{~min}$ from initiation of the reaction.

the fixed time method is the most conventional and simplest, involving the measurement of $\Delta \mathrm{A}$ at $518 \mathrm{~nm}$. Figure 2 shows the relationship between $\mathrm{A}$ and reaction time. It was found that the rate of reaction is proportional to the SCG concentration. The reaction rate was monitored spectrophotometrically by measuring the decrease in absorbance of the characteristic band of amaranth at $518 \mathrm{~nm}$. Therefore, by measuring the decrease in absorbance of amaranth at a fixed time of $0.5-$ $4.0 \mathrm{~min}$ from initiation of the reaction, the SCG contents in the sample can be measured.

3.1. Optimization of Variables. The influence of $\mathrm{H}_{2} \mathrm{SO}_{4}$ concentration, $\mathrm{TBAB}$ concentration, amaranth concentration, periodate concentration, and temperature on the rate of catalyzed and uncatalyzed reactions was studied to find the optimum conditions. 


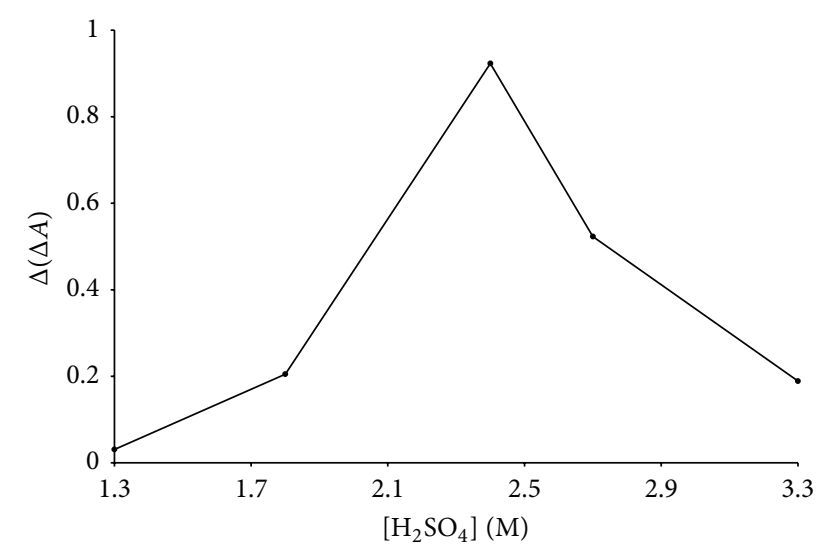

FIGURE 3: Effect of $\mathrm{H}_{2} \mathrm{SO}_{4}$ on the sensitivity. Conditions: SCG;

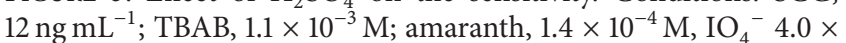
$10^{-4} \mathrm{M}$; temperature, $25^{\circ} \mathrm{C}$.

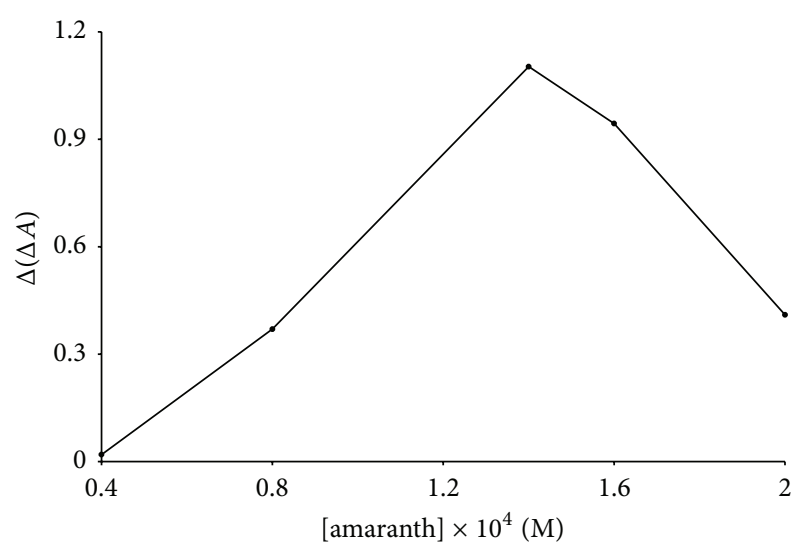

FIGURE 4: Effect of amaranth concentration on the sensitivity. Conditions: $\mathrm{H}_{2} \mathrm{SO}_{4}, 2.4 \mathrm{M}$; SCG; $12 \mathrm{ng} \mathrm{mL}^{-1}$; TBAB, $1.1 \times 10^{-3} \mathrm{M}$; $\mathrm{IO}_{4}{ }^{-} 4.0 \times 10^{-4} \mathrm{M}$; temperature, $25^{\circ} \mathrm{C}$.

The effect of $\mathrm{H}_{2} \mathrm{SO}_{4}$ concentration on the sensitivity was studied in the range of $1.3-3.3 \mathrm{M}$ in the presence of $12 \mathrm{ng} \mathrm{mL}^{-1}$ SCG, $1.0 \times 10^{-3} \mathrm{M}$ TBAB, $1.4 \times 10^{-4} \mathrm{M}$ amaranth, and 4.0 $\times 10^{-4} \mathrm{M} \mathrm{IO}_{4}{ }^{-}$at $25^{\circ} \mathrm{C}$. Figure 3 shows that by increasing $\mathrm{H}_{2} \mathrm{SO}_{4}$ values up to $2.4 \mathrm{M}$, the net reaction rate increases, whereas higher $\mathrm{H}_{2} \mathrm{SO}_{4}$ values cause decreasing the sensitivity. This phenomenon is due to the fact that in acidic medium, amaranth was protonated. Therefore, $\mathrm{a}_{2} \mathrm{SO}_{4}$ concentration of $2.4 \mathrm{M}$ was selected for further study.

Figure 4 shows the influence of amaranth concentration on the sensitivity in the range of $0.4-2 \times 10^{-4} \mathrm{M}$. The results show that by increasing amaranth concentration up to 1.4 $\times 10^{-4} \mathrm{M}$, the net reaction rate increases, whereas greater amounts of the dye decrease the sensitivity. This may be due to the aggregation of the dye in higher concentration. Therefore, an amaranth concentration of $1.4 \times 10^{-4} \mathrm{M}$ was selected for the study.

The effect of periodate on the reaction rate was studied in the range of $2.0-8.0 \times 10^{-4} \mathrm{M}$. Figure 5 shows that the net reaction rate increases with periodate up to $4.0 \times 10^{-4} \mathrm{M}$,

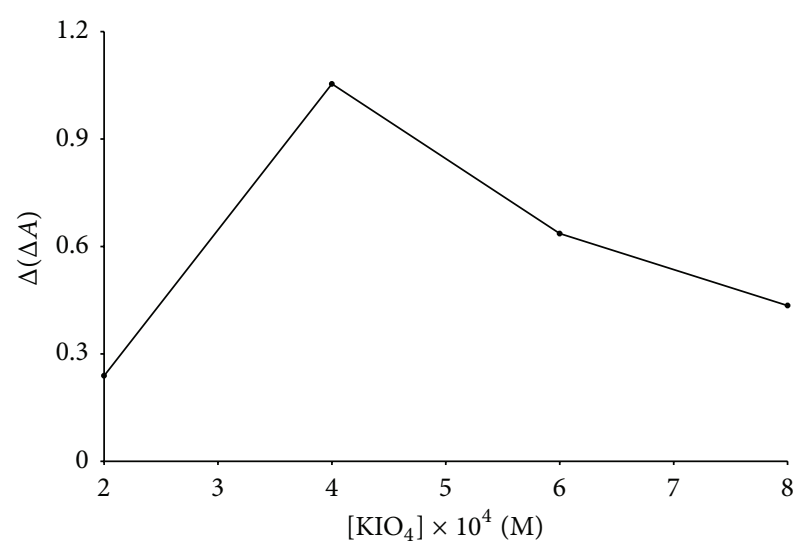

FIGURE 5: Effect of $\mathrm{IO}_{4}{ }^{-}$on the sensitivity. Conditions: $\mathrm{H}_{2} \mathrm{SO}_{4}$, $2.4 \mathrm{~mol} \mathrm{~L}^{-1}$; SCG; $12 \mathrm{ng} \mathrm{mL}^{-1}$; TBAB, $1.1 \times 10^{-3} \mathrm{M}$; amaranth, $1.4 \times$ $10^{-4} \mathrm{M}$; temperature, $25^{\circ} \mathrm{C}$.

whereas the reaction rate decreases with increasing periodate concentration from $4.0 \times 10^{-4} \mathrm{M}$ to greater values. This means that the rate of uncatalyzed reaction increases with periodate concentration $\left(>4.0 \times 10^{-4}\right)$ to a greater extent than the catalyzed reaction, and the difference between the rates of catalyzed and uncatalyzed reactions $\left(\Delta \mathrm{A}_{\mathrm{s}}-\Delta \mathrm{A}_{\mathrm{b}}\right)$ diminishes at higher periodate concentration. Thus, a periodate concentration of $4.0 \times 10^{-4} \mathrm{M}$ was selected for further study.

In many reactions, suitable micelles can affect the rate of reactions [10-15]. A micelle usually can be formed by the aggregation of charged organic molecules. These micelles have the same charge at the outer sphere. For those reactions which have charged species, these micelles can affect the rate of reaction by increasing the effective collisions. In order to choose an appropriate micellar system to enhance the rate of reaction, one should take into account the type of charge of the reactants because the accelerating effect of micelles arises essentially due to electrostatic and hydrophobic interactions between the reaction and micellar surfaces [16]. Cationic (CTAB, HDPB, TBAB, and HDPC), anionic (SDS), and nonionic (Triton X-100) micelles were tested at a concentration greater than the critical micelle concentration (CMC) [13]. The results are shown in Table 1. SCG and amaranth are positively charged, and periodate is negatively charged. Therefore, it seems logical to think that the cationic micelles can enhance the rate of SCG-amaranth-periodate reaction. In fact, CTAB, HDPB, TBAB, and HDPC increased sensitivity, but TBAB increased sensitivity more than HDPB, TBAB, and HDPC; thus, TBAB was chosen for the study (Table 1).

The effect of TBAB concentration on the rate of reaction was studied in the range of $0-2 \times 10^{-3} \mathrm{M}$. The sensitivity increases with increasing $\mathrm{TBAB}$ concentration up to $1.0 \times$ $10^{-3} \mathrm{M}$ and decreases at higher concentrations. This is due to the high aggregation of the surfactant and change in the molar absorptivity of the amaranth in the solution. Therefore, a final concentration of $1.0 \times 10^{-3} \mathrm{M}$ was selected as the optimum concentration of TBAB (Figure 6).

Figure 7 shows the influence of reaction temperature on the sensitivity studied in the range of $10-40^{\circ} \mathrm{C}$ with the 
TABLE 1: Surfactants tested as potential micellar catalysts for the enhanced rate of SCG-amaranth- $\mathrm{IO}_{4}{ }^{-}$reaction.

\begin{tabular}{lccc}
\hline Surfactant & Type & $\begin{array}{c}\text { CMC } \\
\mathbf{M}\end{array}$ & Micellar catalysis \\
\hline SDS & Anionic & $8.1 \times 10^{-3}$ & Positive \\
CTAB & Cationic & $1.3 \times 10^{-3}$ & Positive \\
HDPB & Cationic & $6.5 \times 10^{-4}$ & Positive \\
TBAB & Cationic & $7.5 \times 10^{-5}$ & Positive \\
HDPC & Cationic & $2.4 \times 10^{-4}$ & Negative \\
Triton X-100 & Nonionic & $3.0 \times 10^{-4}$ & Negative \\
\hline
\end{tabular}

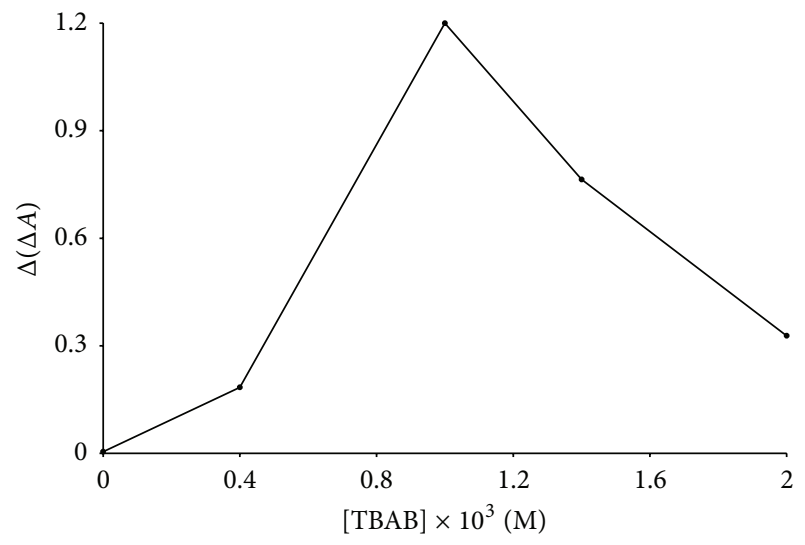

Figure 6: Effect of TBAB on the sensitivity. Conditions: $\mathrm{H}_{2} \mathrm{SO}_{4}$, $2.4 \mathrm{~mol} \mathrm{~L}^{-1}$; SCG; $12 \mathrm{ng} \mathrm{mL}{ }^{-1}$; amaranth, $1.4 \times 10^{-4} \mathrm{M} \mathrm{IO}_{4}{ }^{-} 4.0 \times$ $10^{-4} \mathrm{M}$; temperature, $25^{\circ} \mathrm{C}$.

optimum other reagent concentrations. The results showed that by increasing temperature up to $25^{\circ} \mathrm{C}$, the net reaction rate increases, whereas higher temperature values cause decreasing the sensitivity $\left(\Delta \mathrm{A}_{\mathrm{s}}-\Delta \mathrm{A}_{\mathrm{b}}\right)$.

3.2. Calibration Graph, Precision, and Limit of Detection. The calibration graph was linear for SCG concentration in the range of $4-36 \mathrm{ng} \mathrm{mL}^{-1}$ with the regression equation of $\Delta \mathrm{A}$ $=0.017 \mathrm{C}-1.39$ with $(r=0.996 n=10)$, where $\Delta \mathrm{A}$ is the change in absorbance for the sample reaction for 0.5$4.0 \mathrm{~min}$ from initiation of the reaction (catalytic reaction) and $\mathrm{C}$ is the SCG concentration in $\mathrm{ng} \mathrm{mL}^{-1}$. The limit of detection (defined as $\mathrm{C}_{\mathrm{L}}=3 \mathrm{~S}_{\mathrm{b}} / \mathrm{m}$, where $\mathrm{C}_{\mathrm{L}}, \mathrm{S}_{\mathrm{b}}$, and $\mathrm{m}$ are limits of detection, standard deviation of the blank signal, and slope of the calibration graph, resp.) is equal to $2.7 \mathrm{ng} \mathrm{mL}^{-1}$ SCG. The relative standard deviation (RSD) for ten replicate determination of 12,20 , and $28 \mathrm{ng} \mathrm{mL}^{-1}$ SCG is $0.40 \%, 0.32 \%$, and $0.53 \%$, respectively.

3.3. Interference Study. In order to assess the application of the proposed method to synthetic samples, the effect of various ions on the determination of $4 \mathrm{ng} \mathrm{mL}^{-1}$ SCG was studied. The tolerance limit was defined as the concentration of added ions causing a relative error less than $3 \%$, the results are summarized in Table 2. The results show that this method is relatively selective for SCG determination.

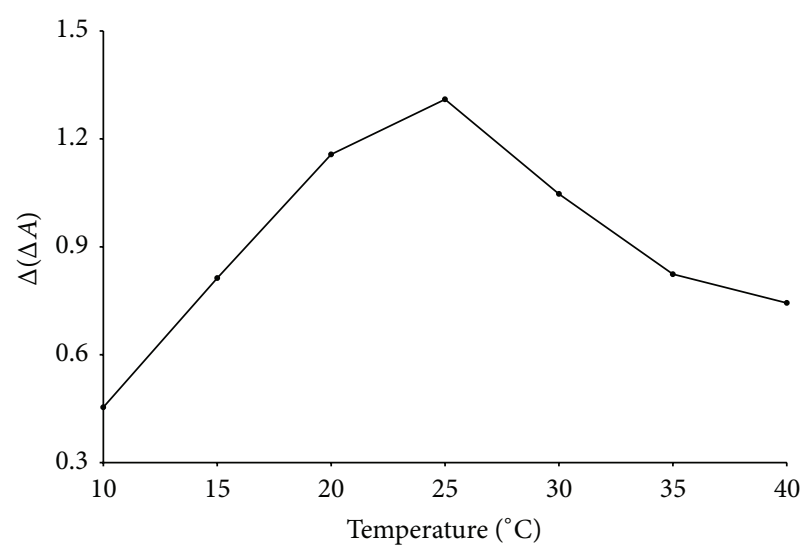

FIgURE 7: Effect of temperature on the sensitivity. Conditions: $\mathrm{H}_{2} \mathrm{SO}_{4}, 2.4 \mathrm{M}$; SCG; $12 \mathrm{ng} \mathrm{mL}^{-1}$; TBAB, $1.0 \times 10^{-3} \mathrm{M}$; amaranth, 1.4 $\times 10^{-4} \mathrm{M}, \mathrm{IO}_{4}^{-} 4.0 \times 10^{-4} \mathrm{M}$.

TABLE 2: Effect of foreign ions on the determination of $12 \mathrm{ng} \mathrm{mL} \mathrm{m}^{-1}$ SCG.

\begin{tabular}{lc}
\hline Foreign species & $\begin{array}{c}\text { Tolerated ratio } \\
W_{\text {species }} / W_{\text {SCG }}\end{array}$ \\
\hline $\mathrm{NO}_{3}{ }^{-}, \mathrm{SO}_{3}{ }^{2-}, \mathrm{I}^{-}, \mathrm{CH}_{3} \mathrm{COO}^{-}, \mathrm{S}_{2} \mathrm{O}_{8}{ }^{2-}, \mathrm{K}^{+}, \mathrm{Ba}^{2+}$, & \\
$\mathrm{Pb}^{2+}, \mathrm{Ni}^{2+}, \mathrm{Na}^{+}, \mathrm{Mg}^{2+}, \mathrm{Cd}^{2+}, \mathrm{Al}^{3+}, \mathrm{Zn}^{2+}, \mathrm{Se}^{4+}$, & 1000 \\
$\mathrm{Cr}^{3+}$, and $\mathrm{Co}^{2+}$ & \\
$\mathrm{Hg}^{2+}$ & 800 \\
$\mathrm{Ag}^{+}$ & 500 \\
$\mathrm{Cl}^{-}$ & 100 \\
\hline
\end{tabular}

TABLE 3: Determination of SCG in synthetic samples.

\begin{tabular}{lccc}
\hline Sample & $\begin{array}{c}\text { SCG added } \\
\text { ng mL }^{-1}\end{array}$ & $\begin{array}{c}\text { SCG found } \\
\text { ng mL }^{-1}\end{array}$ & $\begin{array}{c}\text { Recovery } \\
\%\end{array}$ \\
\hline \multirow{3}{*}{ Human serum } & 6 & 6.3 & 105 \\
& 7 & 7.2 & 102 \\
Urine & 8 & 7.9 & 99 \\
& 6 & 5.5 & 95 \\
& 7 & 7.4 & 105 \\
& 8 & 8.3 & 103 \\
\hline
\end{tabular}

3.4. Sample Analysis. In order to evaluate the applicability of the proposed method, urine and human serum samples were analyzed to determine SCG contents. The results are presented in Table 3. Good recoveries with precise results show good reproducibility and accuracy of the method.

\section{Conclusion}

The kinetic spectrophotometric method developed for SCG determination is inexpensive and readily available, allows rapid determination at low operating costs, and shows simplicity and adequate selectivity. The detection limit of the proposed method was $2.7 \mathrm{n} \mathrm{mL}^{-1}$. The method was found to be of very good precision and accuracy, in relation to the 
other kinetic procedures. Therefore, the method could be proposed for biological samples.

\section{Acknowledgment}

The authors are thankful to the Majlesi and Shahreza Branches, Islamic Azad University for the support of this work.

\section{References}

[1] O. A. Aswania, S. A. Corlett, and H. Chrystyn, "Validation of a high-performance liquid chromatography assay for urinary nedocromil sodium following oral and inhaled administration," Journal of Chromatography B: Biomedical Applications, vol. 718, no. 2, pp. 290-295, 1998.

[2] M. L. Ozoux, J. Girault, J. M. Malgouyat, and O. Pasquier, "Determination of sodium cromoglycate in human plasma by liquid chromatography-mass spectrometry in the turbo ion spray mode," Journal of Chromatography B: Biomedical Sciences and Applications, vol. 765, no. 2, pp. 179-185, 2001.

[3] F. C. Pereira, A. G. Fogg, and M. V. B. Zanoni, "Regeneration of poly-L-lysine modified carbon electrodes in the accumulation and cathodic stripping voltammetric determination of the cromoglycate anion," Talanta, vol. 60, no. 5, pp. 1023-1032, 2003.

[4] A. G. Fogg and N. Fayad, "Differential pulse polarographic determination of disodium cromoglycate in urine," Analytica Chimica Acta, vol. 102, no. C, pp. 205-210, 1978.

[5] K. Brown, J. J. Gardner, and W. J. S. Lockley, "Radioimmunoassay of sodium cromoglycate in human plasma," Annals of Clinical Biochemistry, vol. 20, no. 1, pp. 31-36, 1983.

[6] R. Leavitt, W. H. Farmer, P. Paterson, and P. Firby, "Sodium cromoglycate in race horses: development of enzyme-linked immunosorbent assay (ELISA) screening and gas chromatograph/mass spectrometry confirmation techniques," Journal of the Canadian Society of Forensic Science, vol. 26, no. 1, pp. 19-32, 1993.

[7] E. Iwasaki, M. Yamaura, and M. Baba, "Assessment of the amount of drug deposited in the lungs of asthmatic children using disodium cromoglycate as the marker," Japanese Journal of Allergology, vol. 42, no. 8, pp. 907-913, 1993.

[8] J. J. Gardner, "Determination of sodium cromoglycate in human urine by high-performance liquid chromatography on an anion-exchange column," Journal of ChromatographyBiomedical Applications, vol. 305, no. 1, pp. 228-232, 1984.

[9] A. A. Ensafi, M. A. Chamjangali, and H. R. Mansour, "Catalytic spectrophotometric determination of ruthenium by flow injection method," Talanta, vol. 55, no. 4, pp. 715-720, 2001.

[10] M. Keyvanfard and K. Alizad, "A spectrophotometric flow injection method for determination of ultratrace amounts of phenylhydrazine by its inhibition effect on the reaction of thionin and nitrite," Journal of Chemistry, vol. 2013, Article ID 258605, 5 pages, 2013.

[11] A. A. Ensafi and M. Keyvanfard, "Kinetic-spectrophotometric determination of tellurium (IV) by its catalytic effect on the reduction of thionine by sodium sulfide in cationic micellar medium," International Journal of Environmental \& Analytical Chemistry, vol. 83, no. 5, pp. 397-404, 2003.

[12] A. A. Ensafi and M. Keyvanfard, "Kinetic spectrophotometric method for the determination of rhodium by its catalytic effect on the oxidation of o-toluidine blue by periodate in micellar media," Journal of Analytical Chemistry, vol. 58, no. 11, pp. 10601064,2003

[13] M. Keyvanfard and A. Sharifian, "Kinetic spectrophotometric method for the determination of selenium(IV) by its catalytic effect on the reduction of spadns by sulphide in micellar media," Journal of Analytical Chemistry, vol. 61, no. 6, pp. 596-600, 2006.

[14] M. Keyvanfard and K. Alizad, "Kinetic determination of phenylhydrazine by its catalytic effect on the reaction between tertrophene blue and bromate in acidic and micellar medium," Asian Journal of Chemistry, vol. 23, no. 10, pp. 4433-4437, 2011.

[15] M. Keyvanfard and K. Alizad, "A simple and selective spectrophotometric flow injection method for the determination of ultra trace amounts of phenylhydrazine by its inhibition effect on the reaction of victoria blue $\mathrm{B}$ and bromate in micellar medium," Journal of Analytical Chemistry, vol. 68, no. 5, pp. 423-428, 2013.

[16] S. Rubio and D. Pérez-Bendito, "Micellar media in kinetic determinations," Analytica Chimica Acta, vol. 224, no. 2, pp. 185-198, 1989. 

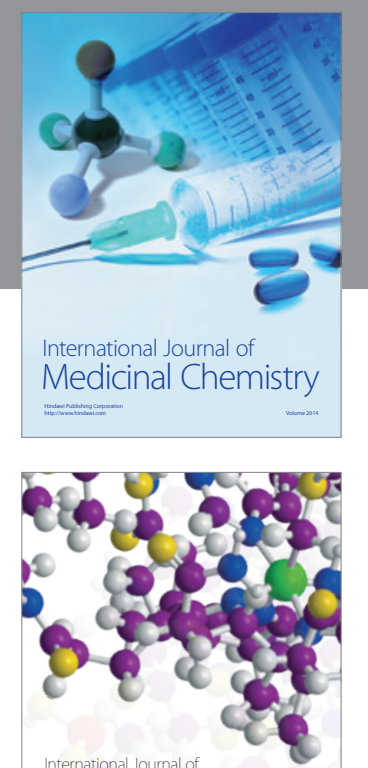

\section{Carbohydrate} Chemistry

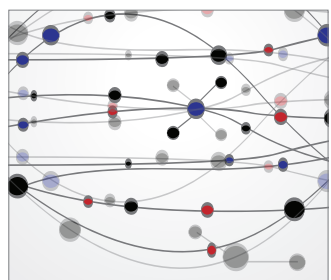

The Scientific World Journal
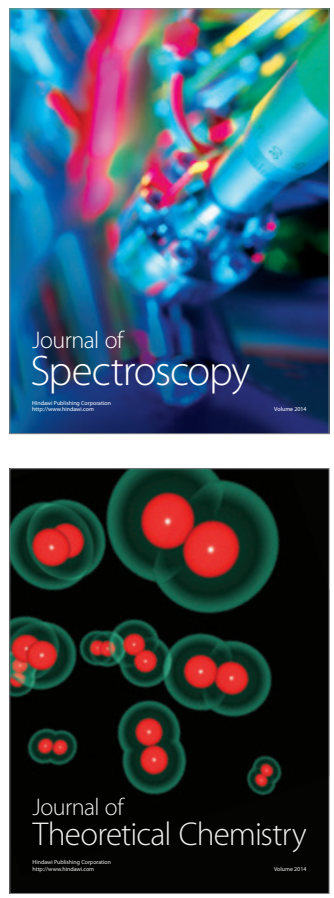
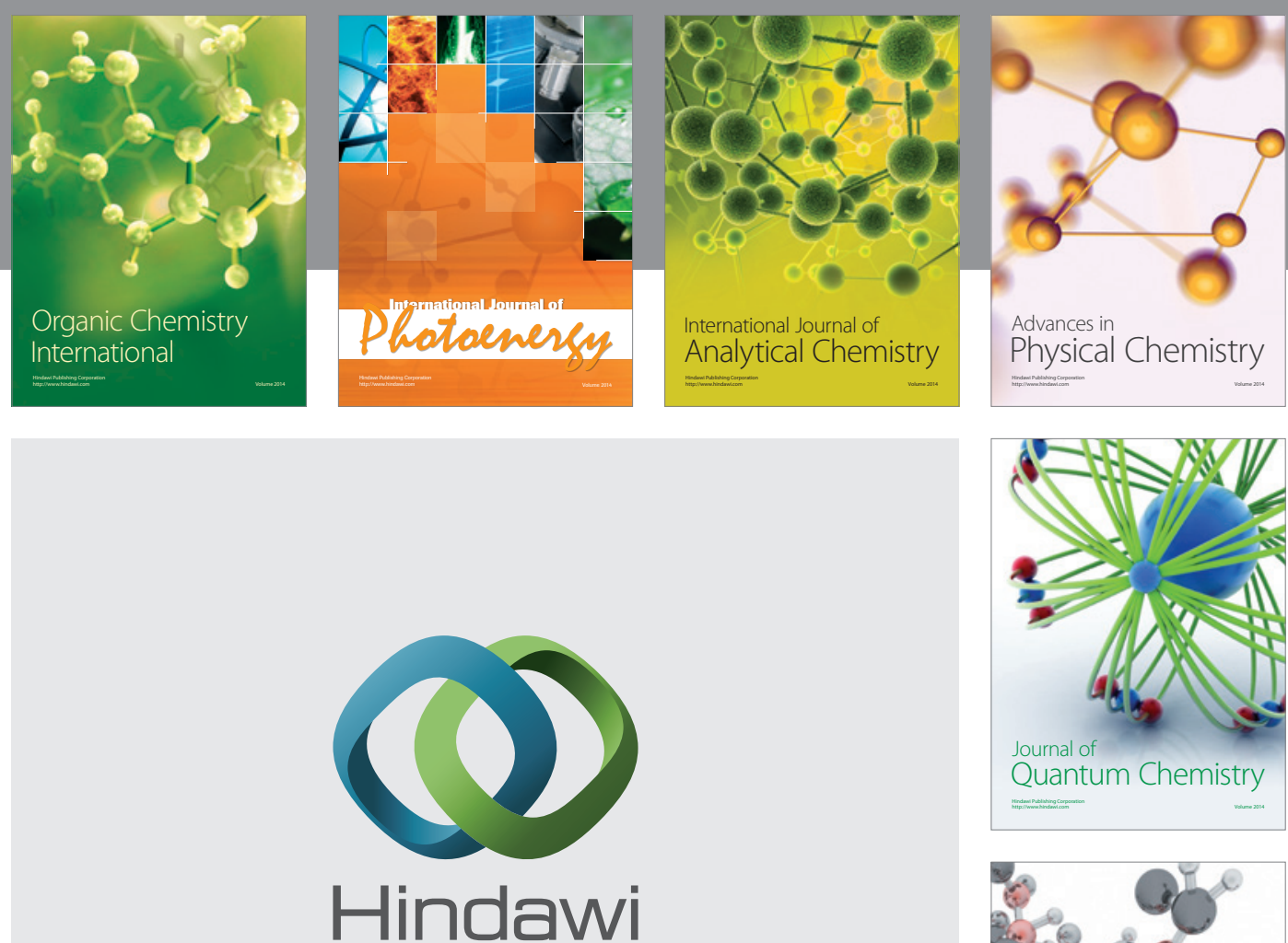

Submit your manuscripts at

http://www.hindawi.com

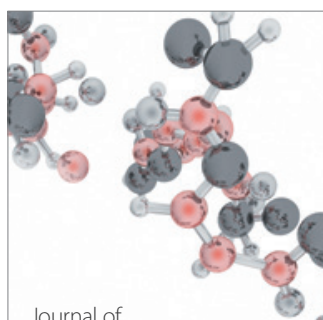

Analytical Methods

in Chemistry

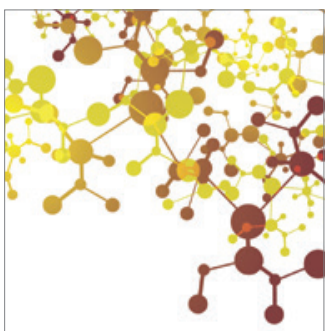

Journal of

Applied Chemistry

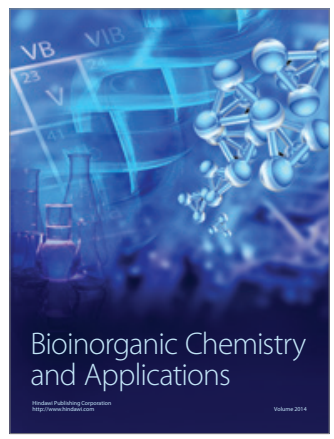

Inorganic Chemistry
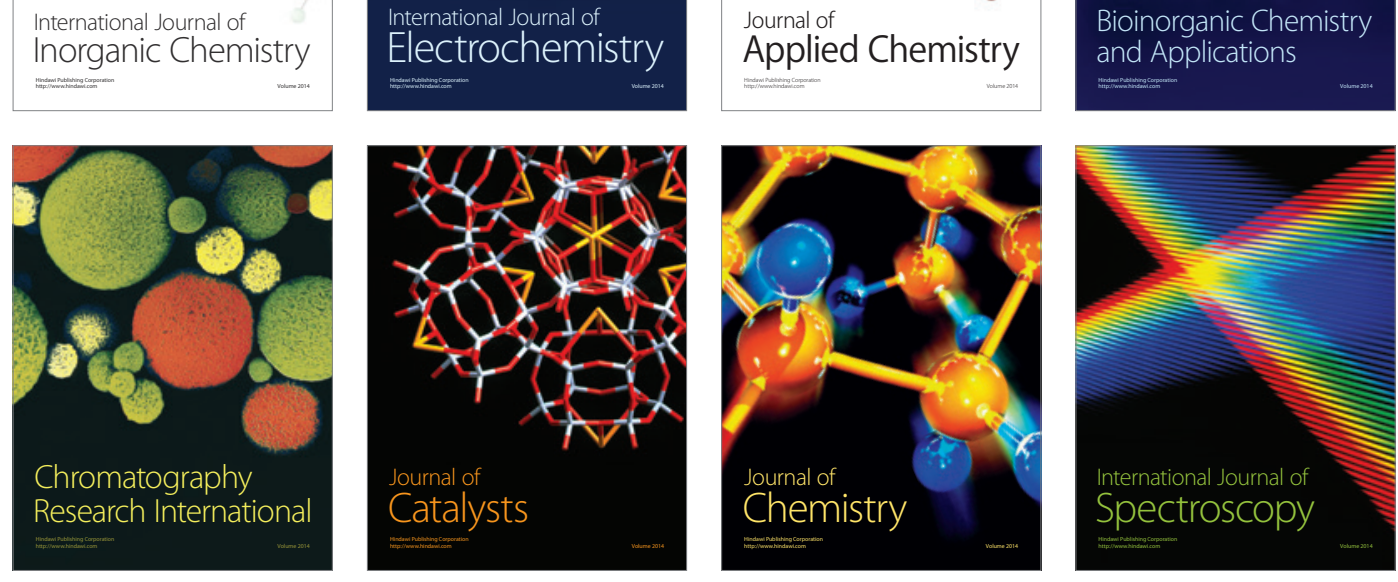